\title{
La política exterior como política pública. Incidencia de las variables internas en la formulación de la política exterior a partir de un estudio de caso: la posición de la Argentina ante el conflicto por el Chaco Boreal entre Paraguay y Bolivia \\ Maximiliano Zuccarino*
}

\section{Resumen}

El presente trabajo se propone avanzar en la construcción de un marco teórico e interpretativo que permita explicar y comprender la formula-

\footnotetext{
* Miembro de la planta estable del Centro de Estudios Interdisciplinarios en Problemáticas Internacionales y Locales (CEIPIL), UNCPBA - Comisión de Investigaciones Científicas de la Provincia de Buenos Aires (CICPBA).
}

Código de Referato: SP.242.XLIV/18

http://dx.doi.org/10.22529/sp.2018.44.03

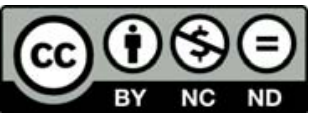

STUDIA POLITICAE

\$g

Número 44 otoño 2018 - pág. 43-74

Publicada por la Facultad de Ciencia Política y Relaciones Internacionales, de la Universidad Católica de Córdoba, Córdoba, República Argentina. 
ción de la política exterior, de los Estados en general y de la Argentina en particular, a partir de conceder especial atención a la incidencia de los factores internos en el proceso de formulación de la misma, partiendo de la consideración que la política exterior es una más de las múltiples políticas públicas. Para ello, se ha tomado como estudio de caso la actuación de la Argentina en el conflicto por el Chaco Boreal entre Paraguay y Bolivia — cuyo punto cúlmine lo constituyó la Guerra del Chaco (19321935) entre estos países - puesto que la misma resulta paradigmática teniendo en cuenta que la posición del país — actuando a la vez como parte interesada y mediador donde se llevaron a cabo las negociaciones de paz - fue la resultante de la confluencia de una serie de factores que van desde intereses “de Estado” económicos, geoestratégicos y militares, hasta aquellos propios de la clase dirigente a cargo del gobierno, pasando por los de empresarios argentinos con capitales invertidos en la región en disputa.

Palabras clave: Políticas Públicas - Política Exterior Argentina - Variables o Factores Internos - Guerra del Chaco

\begin{abstract}
This paper intends to move forward in the construction of a theoretical and interpretative framework that allows to explain and to understand the formulation of the foreign policy, of the States in general and of Argentina in particular, paeing special attention to the incidence of the internal factors in the process of its formulation, since it is considered one of the many public policies. To this end, the role played byArgentina in the Chaco Boreal conflict between Paraguay and Bolivia, whose culminating point was the Chaco War (1932-1935) between these countries has been taken as a case study. We consider it paradigmatic sine the position of the country - acting as both an interested and mediating party in which peace negotiations were carried out- was the result of the confluence of several factors, ranging from economic, geostrategic and military "State interests" to those of the ruling class in charge of the government, and those of Argentine entrepreneurs with capital invested in the region in dispute.
\end{abstract}

Keywords: Public Policies - Argentine Foreign Policy - Internal Variables or Factors - Chaco War

\title{
Introducción
}


Argentina en particular, a partir de la combinación de variables tanto internas como externas al ámbito territorial en donde las mismas son concebidas y ejecutadas. Dentro de ellas, se concederá especial atención a la incidencia de los factores internos en el proceso, partiendo de la consideración de que la política exterior es una más de las múltiples políticas públicas y, por lo tanto, tiende a satisfacer tanto los intereses del Estado en función del modelo de desarrollo político-económico adoptado, como así también aquellos propios de la clase dirigente que se encuentre en ejercicio del gobierno.

Para llevar adelante esta investigación, se ha tomado como estudio de caso la actuación de la Argentina —a la vez como mediador y parte interesadaen el conflicto y diferendo limítrofe por el Chaco Boreal entre el Paraguay y Bolivia — cuyo punto cúlmine lo constituyó la Guerra del Chaco entre estos países- así como en las posteriores negociaciones de paz.

Cabe señalar que el mencionado acontecimiento bélico se extendió por un lapso de tres años (junio/septiembre 1932-junio 1935), y concluyó, desde un punto de vista estrictamente militar, con la victoria del Paraguay. Se trata del conflicto armado más importante acaecido en suelo americano a lo largo de todo el siglo XX, atendiendo a las pretensiones territoriales de una y otra parte, a la vastedad de recursos y hombres movilizados y al armamento utilizado, en muchos casos como banco de pruebas de cara a la Segunda Guerra Mundial. También el aspecto geoestratégico jugó un rol importante en la contienda, puesto que la búsqueda de una salida atlántica por parte de Bolivia —que había perdido su litoral marítimo a manos de Chile en la Guerra del Pacífico (1879-1883) — fue un factor determinante para el estallido de la misma, como así también lo fue el nacionalismo de la clase dirigente y el pueblo paraguayos, que consideraban al Chaco Boreal como parte integral de su territorio. Asimismo, deben ser tenidos en cuenta los intereses de las petroleras internacionales que operaban en la zona en disputa (Standard Oil y Royal Dutch-Shell) y los de algunos países limítrofes (Argentina, Brasil, Chile) y no limítrofes (Estados Unidos) a los contendientes, que participaron activamente en la resolución de la disputa, cuyas negociaciones de paz duraron también aproximadamente tres años desde el fin de las hostilidades (hasta julio de 1938/enero de 1939) y fueron llevadas a cabo íntegramente en Buenos Aires, desempeñando el Gobierno argentino - y en particular el Canciller Carlos Saavedra Lamas - un papel rector en el transcurso de las mismas.

En función de lo señalado, adquiere importancia el análisis de la situación imperante en Argentina en la década de 1930 y el modelo político-econó- 
mico de desarrollo adoptado, caracterizado, en lo político, por la ruptura del orden constitucional tras el primer golpe de Estado en la historia del país, la llegada de Agustín P. Justo a la Presidencia, la implementación del fraude electoral y la violencia política, y el apoyo brindado al Gobierno Nacional por parte de los políticos conservadores del interior del país nucleados en el Partido Demócrata Nacional (PDN), cuyo exponente por antonomasia fue el empresario azucarero salteño Robustiano Patrón Costas. En el plano económico, bajo un marco de crisis y depresión internacional que afectó profundamente a un país que tenía su economía estructurada en función del comercio exterior, se implementaron medidas dirigidas a una mayor intervención estatal en la economía y al reforzamiento del vínculo comercial estratégico con Gran Bretaña, profundizando de ese modo el modelo de desarrollo basado en la agroexportación, el cual se había mostrado exitoso en los cincuenta años previos y que beneficioso para los grandes grupos económicos vinculados al poder.

En este contexto, la política exterior del país se caracterizaría por la búsqueda de un papel cada vez más preponderante en los asuntos internacionales, a través de la reincorporación a la Sociedad de las Naciones y la actividad político-diplomática desplegada en torno al conflicto del Chaco, caracterizada ésta última por una declaración formal de neutralidad pero que, en la práctica, implicó una actividad incesante y no muy bien disimulada en favor de la causa paraguaya y de confrontación con las posiciones asumidas por otras naciones que, como el Brasil y los Estados Unidos, pretendieron disputarle el liderazgo de las negociaciones pacificadoras.

\section{Marco teórico}

Resulta importante comenzar señalando, siguiendo a Rubén Perina (1988), que la política exterior debe ser entendida como el conjunto de decisiones $\mathrm{y}$ acciones tomadas por los gobernantes de un Estado en respuesta a demandas y determinantes internos y externos, con el objetivo de defender y promover los intereses y valores de ese Estado en el sistema internacional. Esta afirmación debe ser complementada con otras dos: que también la política exterior de los Estados, en tanto política pública, tiende a legitimar y sostener esos valores e intereses hacia el interior del propio país; y que su concepción y ejecución responden asimismo a satisfacer, junto a los intereses del Estado, los de la clase dirigente que coyunturalmente se encuentra en ejercicio del poder. 
Estas premisas, que guiarán la presente investigación, habilitan a otorgar, dentro del análisis, un mayor peso a las variables internas a la hora de interpretar la formulación de la política exterior, sin por ello desconocer la incidencia de los condicionantes externos o sistémicos a los que históricamente - desde el campo disciplinar de las relaciones internacionales y más allá de los avances experimentados en el corpus teórico a los que se hará referencia a continuación- se les ha brindado una atención preferente como factores explicativos del comportamiento externo de los países de la región latinoamericana en general y de la Argentina en particular.

En este sentido, cabe destacar que si bien la literatura sobre las fuentes internas de la política exterior comenzó a desarrollarse en Estados Unidos a fines de la década de 1950 — complementándose en la década siguiente con los trabajos de Pierre Renouvin y su desarrollo del concepto de las "fuerzas profundas" como factores que limitan y condicionan la toma de decisiones en materia internacional (Renouvin y Duroselle, 2000) - el estudio de las mismas no halló eco inmediato en América Latina, donde recibieron mucha menos atención que las variables exógenas debido, entre otros factores, a que allí el enfoque predominante partía de considerar la posición "periférica” de los países de la región, lo cual colocaba al sistema internacional como principal factor condicionante de su comportamiento externo y tendía a subestimar la importancia de los factores internos en la formulación y ejecución de la política exterior (Russell, 1990).

Partiendo de esta realidad, y en sintonía con nuevos enfoques que han ido apareciendo, de lo que se trata es de valorizar la incidencia de las variables internas en el proceso de formulación de la política exterior, destacándose entre ellas la incidencia del modelo político-económico de desarrollo adoptado. Para ello, resultan de suma utilidad los trabajos de una serie de analistas y teóricos provenientes del campo de las relaciones internacionales, entre los que sobresale el politólogo y teórico de las relaciones internacionales alemán Volker Rittberger (2004), quien hace referencia a la corriente del liberalismo utilitario - que enfatiza en lo que el autor denomina el nivel sub-sistémico, buscando explicar la política exterior de los Estados “desde abajo" al focalizarse en lo que sucede hacia el interior del país-, en oposición al neorrealismo, el cual coloca el acento en los incentivos, constreñimientos y estándares de comportamiento del sistema internacional como determinantes de la conducta internacional de los Estados. La teoría constructivista, por último, considera que ambos factores, internacionales y domésticos, afectan la actuación de los Estados en la arena internacional. Roberto Miranda (2011), por su parte, señala la diferencia entre los postu- 
lados realistas y los del internacionalismo liberal y del institucionalismo internacional, que consideran a las variables domésticas, especialmente el tipo de régimen imperante, como eje de las decisiones de política exterior; así como el estructuralismo, que analiza la política exterior como un instrumento de la clase dominante, para finalmente centrar su análisis en otros enfoques que han ido surgiendo, los cuales combinan componentes domésticos e internacionales sin límite alguno.

Dentro de esas corrientes teóricas anglosajonas se destaca asimismo el institucionalismo neoliberal, el cual considera a los factores nacionales como centrales para entender la política exterior, ya que es en ese campo donde ejercen su influencia los grupos o individuos que participan en la definición de políticas, además de articular coaliciones y redes con sus contrapartes en el exterior para incidir en los procesos internacionales (Keohane y Nye, 1988). En relación a esto, Robert Putnam (1988) considera que los factores internos pueden determinar la política exterior de un país, sea para alcanzar los fines propios del Estado o de los grupos que influencian su accionar; éstos intentan determinar las políticas de gobierno mientras los decisores de política procuran mantener el poder, por lo cual se establecen coaliciones entre ambos.

En relación a estos grupos dirigentes encargados de la formulación de la política exterior, resulta pertinente el análisis de Lawrence Stone (1986), quien aporta el concepto de la prosopografía, o método prosopográfico, al cual define como "la investigación retrospectiva de las características comunes a un grupo de protagonistas históricos, mediante un estudio colectivo de sus vidas" (Stone, 1986: 61). Siguiendo al autor, su valor consiste en que permite descubrir las intenciones de fondo que subyacen bajo la retórica política o analizar las filiaciones sociales y económicas de las agrupaciones políticas, a partir de un estudio del papel social de grupos con un cierto estatus, tales como detentadores de títulos, funcionarios públicos, etc., con el objeto de demostrar la fuerza cohesiva del grupo en cuestión, vinculado por una misma sangre, similares antecedentes educativos, intereses económicos comunes, así como prejuicios, ideales e ideología.

En esta línea que tiende a valorizar factores o variables internas, Helen Ingram y Suzanne Fiederlein (1988) afirman que el estudio de las influencias domésticas sobre la política exterior es un campo en crecimiento que destaca el rol jugado por distintas fuerzas e instituciones políticas tales como el Poder Legislativo, la burocracia, los Estados (provincias), la opinión pública y determinados grupos de interés. Manfred Wilhelmy (1991), por su parte, propone un enfoque similar aplicado al caso latinoamericano, 
sosteniendo que la política exterior es una política pública y que, como tal, es susceptible de ser sometida a procesos de análisis análogos a las demás. Partiendo de esa base, subraya la voluntad generalizada de los actores estatales latinoamericanos en el sentido de desarrollar políticas exteriores como componentes esenciales de los respectivos proyectos políticos nacionales.

Pasando de este modo a los análisis elaborados desde esta parte del mundo, Rubén Perina (1988) asevera que el subsistema de política exterior y relaciones internacionales de un Estado-nación consta de tres variables que se afectan mutuamente: las "internas", las “externas" y el conjunto de variables de política exterior y relaciones internacionales propiamente dicho, que vincula las dos anteriores. Dentro de las variables internas, entrarían el tipo de régimen político-económico que controla el Estado; los diferentes actores, gubernamentales o no, que influyen o participan en la formulación y ejecución de la política exterior; la cultura política, es decir, los valores, actitudes, creencias, tradiciones y hábitos que determinan o condicionan el comportamiento de esos actores; la capacidad económica, político-institucional, tecnológica, militar y diplomática del Estado-nación que representan; los recursos o instrumentos con que cuentan los responsables de la política exterior para lograr sus objetivos y los temas que predominan en la agenda. En lo referente a las variables externas, Perina distingue: la estructura jerárquica del sistema internacional (bipolar o multipolar); el patrón de relaciones entre los principales Estados-nación de ese sistema, así como sus capacidades (político-económicas, tecnológicas, militares y diplomáticas) y sus crisis económico-financieras y político-militares, más los cambios tecnológicos y culturales ocurridos hacia su interior y las normas del derecho internacional.

Roberto Russell (1990), por su parte, propone — tomando siempre en cuenta las variables externas, a las cuales los países latinoamericanos son ciertamente sensibles y vulnerables - ampliar el análisis e incorporar las variables internas, tales como la forma de organización política, las percepciones, imágenes e ideologías de los formuladores de políticas, el proceso de toma de decisiones y las pugnas personales y burocráticas (las cuales también inciden a la hora de las decisiones de política exterior). En este proceso, si bien participan actores gubernamentales y no gubernamentales, del país y del extranjero, ejerciendo influencia a través de distintos mecanismos, la adopción de la decisión sólo puede ser realizada por actores gubernamentales domésticos, capacitados a comprometer los recursos de la sociedad. 
En relación al caso concreto argentino, Mario Rapoport y Claudio Spiguel (2005) indican que explicar la historia de la política exterior argentina supone, al enfocar sus lazos con la política interna, analizar su íntima vinculación con la naturaleza socio-histórica del Estado y la estructura económica de la sociedad. Dentro de esta línea, María Natalia Tini (2005), a partir del estudio comparado de Argentina y Paraguay, destaca también la idea de considerar a la política exterior como una política pública más, dando de ese modo relevancia al análisis de los factores internos que inciden en las decisiones en esa materia, tales como los cambios de régimen, el papel de la Cancillería y del Congreso (limitado a la ratificación de tratados y regulaciones internacionales), así como también los valores a los que adhieren los círculos dirigentes.

Otro de los principales exponentes que ha hecho hincapié en la trascendencia del estudio de los factores internos es Marcelo Lasagna (1995), quien destaca como elementos explicativos importantes, si bien no exclusivos, de la conducta exterior de un Estado a las creencias y acciones de los formuladores de políticas en las instituciones burocráticas estatales, quienes se encuentran, a su vez, influidos por la sociedad, especialmente la sociedad política. Asimismo, el autor coloca especial énfasis en el régimen político, por tratarse del centro neurálgico del proceso de toma de decisiones gubernamentales. En este sentido, adquiere gran relevancia el análisis de los principios y valores que justifican las orientaciones de las políticas públicas que adopta dicho régimen, entre ellas la política exterior, la cual se encuentra así condicionada por los principios basales del régimen y por la ideología que abrace el grupo o partido gobernante y la coalición de intereses que lo sustente.

En relación a esto último, afirma el autor que los regímenes autoritarios normalmente tienen una fuerte autonomía de la influencia popular y una autonomía débil de las élites, especialmente de grupos empresariales y/o militares, mientras que en los regímenes democráticos se da la relación inversa. Esto es clave ya que contribuye a configurar la orientación del régimen, la cual da cuenta, por un lado, de las creencias básicas del grupo que gobierna acerca de los asuntos mundiales y cómo ellos se relacionan con los intereses externos e internos del Estado, y por otro, refleja la coalición de intereses sociales, económicos y políticos asociados al régimen. La premisa teórica de este concepto es que todo grupo dirigente deja su impronta tanto en las metas y objetivos del Estado en asuntos externos, como en la naturaleza de la reacción del Estado ante estímulos internacionales. 
Otros autores, como William Hazleton (1987) y Heraldo Muñoz (1987), colocan el acento en diversos factores y actores que influyen en el proceso de toma de decisiones en materia de política exterior por parte de los Estados (especialmente los latinoamericanos), tales como las empresas transnacionales, la teoría realista de poder y las percepciones o imágenes que cada país tiene sobre el sistema internacional, la potencia hegemónica de turno y los Estados vecinos, destacando así la importancia de actores e influencias tanto internos como externos en dicho proceso. En este sentido, Peter Gourevitch (2007) va incluso más allá y advierte sobre la existencia de una interacción y mutua influencia entre política internacional y estructura doméstica, considerando que deberían ser analizadas simultáneamente como un todo.

Finalmente, el politólogo y diplomático chileno Alberto van Klaveren (1984) es uno de los autores que probablemente más claramente sistematiza la cuestión de las variables externas e internas. Dentro de las primeras incluye las perspectivas sistémicas, de la dependencia, cuantitativas sobre dependencia y política exterior y las políticas del poder, ${ }^{1}$ mientras que en relación a los factores internos el autor asevera, refiriéndose al caso latinoamericano, que

"es problemático identificar fuentes puramente domésticas de política exterior en una región donde actores transnacionales de naturaleza tan diversa han establecido vínculos estrechos con grupos locales. Sin embargo, el solo hecho de que estas fuerzas transnacionales actúen a través de agentes locales y que, en consecuencia, ejerzan una influencia mediatizada, indica que todavía es posible hablar de variables internas. Además, resultaría absurdo buscar fuerzas externas tras cada decisión de política exterior en la región” (van Klaveren, 1985: 34).

Dentro de los aspectos internos, el autor destaca la importancia de la orientación del régimen, con especial énfasis en la distinción entre regímenes democráticos y autoritarios, aunque también señalando como factor trascendente la estrategia de desarrollo adoptada como medio para modificar

1 Dentro del enfoque de las políticas se enmarca el análisis tradicional de equilibrio de poder, el cual considera a Sudamérica como un escenario típico de competencia regional, donde países como Brasil y Argentina rivalizan en la Cuenca del Plata y en el Atlántico Sur, lo cual repercute con especial fuerza en los países más débiles y pequeños de la región, como Bolivia, Paraguay y Uruguay, cuyos sistemas económicos y políticos son constantemente penetrados por sus vecinos más poderosos. 
variables internacionales en términos favorables a los objetivos de la misma. Por último, dentro del análisis de la orientación del régimen, señala el estilo y enfoque característico de política exterior de un país proveniente de una cierta tradición histórica. Los "procesos de toma de decisiones y política interna" constituyen la segunda variable interna de relevancia, y se diferencia de la anterior en que tiende a desagregar más el contexto interno, centrándose en participantes, tipos de procesos de toma de decisiones e influencias domésticas que intervienen en el campo de la política exterior, cuyo número y complejidad tiende a ser mayor en los países más grandes y desarrollados de la región, como la Argentina o Brasil. Finalmente, Van Klaveren menciona dos últimas variables internas: la política burocrática —que explica siguiendo a Graham Allison (1971) — y el liderazgo, pero las coloca en un segundo orden de importancia y pertinencia para los países de la región.

A los autores citados cabría añadir otros, cuyos trabajos han sido publicados más recientemente. En este sentido, hay que mencionar la línea de investigación seguida por el Centro de Estudios en Relaciones Internacionales de Rosario (CERIR), que valoriza la incidencia de las variables domésticas en la formulación de la política exterior. Esteban Actis (2012) y Eliana Calderón (2014), por ejemplo, proponen esta mirada para analizar distintos aspectos de la política exterior brasileña: mientras el primero destaca a partidos políticos, cámaras empresariales, sindicatos, y al parlamento como actores que juegan un rol activo, cuestionando la antigua lógica de conducción vertical de las cancillerías; Calderón identifica la articulación de tres variables domésticas: la capacidad estatal de gestión, el proyecto político-ideológico nacional y la influencia del sector militar. Anabella Busso (2014), por su parte, sostiene que, sin desconocer el impacto de las variables sistémicas, los vaivenes de la política exterior se explican mayoritariamente por causas internas entre las cuales se destacan las crisis político-económicas, las tensiones entre los distintos modelos de desarrollo y sus respectivas estrategias de inserción internacional —liberalismo y alineamiento por una parte versus desarrollismo y autonomía por la otra- y las variaciones en la concepción de democracia. Finalmente, Ornela Fabani (2016), siguiendo a algunos autores árabes contemporáneos y a otros clásicos como James Rosenau (1997), reafirma la necesidad de adoptar un enfoque que combine variables internas y externas (o "intermésticas") a la hora de analizar la política exterior de un Estado.

Además de estas contribuciones, otros autores contemporáneos han puesto de relieve la necesidad de contemplar los condicionantes domésticos en la 
formulación de la política exterior. Entre ellos se puede mencionar a Mauricio Alice (2009), que analiza cómo Argentina elabora su estrategia internacional y determina sus tácticas en función de los intereses y objetivos nacionales, lo cual, a su juicio, supone observar el perfil, comportamiento y condicionantes de los encargados de ejecutar la política exterior. En ese contexto, el autor destaca a los actores privados —opinión pública, medios de prensa, agrupaciones de determinados sectores políticos o económicos, organizaciones no gubernamentales y representativas de la sociedad civil, entre otros - los cuales pueden llegar a ejercer una considerable influencia.

Leandro Sánchez (2013), aborda la participación del "cuerpo decisional legislativo” en la confección de la agenda de política exterior, entendiéndolo como un condicionante interno en tanto responde en buena medida a la relación de fuerzas existente en la sociedad y actúa como intermediario y articulador entre el poder institucional y los ciudadanos. Pablo Valenzuela (2013), mientras tanto, aporta el concepto de "actores domésticos autónomos”, entendidos como grupos de interés que buscan llevar a cabo de manera legítima sus propias agendas a partir de influenciar al gobierno para que adopte o deje de adoptar ciertas orientaciones de política pública que pueden dañar sus intereses.

En esa línea, Luis Schenoni y Alejo Ferrandi Aztiria (2014) reconocen la influencia de múltiples grupos de interés domésticos en la toma de decisiones en política exterior, y van más allá al proponer que el incremento en la cantidad de actores involucrados en dicho proceso genera tres efectos en la misma: mayor estabilidad, mayor poder de negociación y mayor poder de agenda. Hugo Dalbosco (2014), por su parte, toma elementos de tres enfoques teóricos de la ciencia política para estudiar la política exterior: la teoría de las élites, la teoría de la burocracia (el servicio diplomático profesional en este caso) y el análisis de políticas públicas. Y añade otra cuestión decisiva a analizar: el texto de la Constitución Nacional, que establece dos grandes actores con competencia en la materia: el Presidente de la Nación y el Congreso, aunque en un plano de desigualdad a favor del primero.

\section{Incidencia de los condicionantes internos en la formulación de la política exterior argentina hacia el conflicto del Chaco Boreal}

La década de 1930 estuvo signada por profundos y, en algunos casos, perdurables cambios tanto en la política como en la economía argentinas. En 
el primero de esos ámbitos, se destacan la ruptura del orden constitucional mediante el primer golpe de Estado en la historia del país y la posterior llegada de un militar, Agustín P. Justo, a la Presidencia de la Nación (19321938) a través de la denominada Concordancia, una coalición política que se mantendría en el poder hasta 1943 mediante el fraude, la corrupción y el apoyo mayoritario de políticos conservadores del interior del país, cuyo representante más notorio fue el empresario azucarero salteño Robustiano Patrón Costas. El análisis del papel desempeñado por la oposición política durante ese periodo resulta asimismo de gran trascendencia a la hora de comprender las reglas del juego político interno: tanto el socialismo y el demoprogresismo en el Congreso, como la UCR desde la ilegalidad (hasta 1935), principalmente, hicieron oír sus reclamos y manifestaron sus críticas hacia la conducción oficialista en diferentes ámbitos, dentro de los cuales la política exterior, caracterizada por un papel cada vez más activo en los asuntos internacionales a través de la participación en la Sociedad de las Naciones, fue uno de los más controvertidos.

En cuanto al aspecto económico, la década se inició en un marco de crisis y depresión internacional que afectó profundamente a un país que tenía su economía estructurada en función del comercio exterior. Ante ello, la industrialización sustitutiva de importaciones, la creciente intervención estatal en la economía y el reforzamiento del vínculo estratégico con Gran Bretaña (Pacto Roca-Runciman, 1933) en favor de un modelo de desarrollo basado en la agroexportación que beneficiaba a los grandes hacendados cercanos al poder, fueron las respuestas ensayadas, aun pese a la creencia generalizada en las altas esferas gubernamentales de que se trataba de un fenómeno pasajero (Macor, 2001). Asimismo, la evolución del sector petrolífero y la actuación de las principales empresas extranjeras en el país en relación a la firma estatal, Yacimientos Petrolíferos Fiscales (YPF), constituye otro punto relevante dentro de la política económica e incluso internacional de la Argentina en el periodo bajo estudio.

Todas estas cuestiones, cabe señalarlo, pueden ser analizadas a partir de las variables propuestas por Anabella Busso (2014), a saber: se trataba de un marco de crisis político-económica en el cual se dio, quizás por primera vez en la Argentina, una tensión entre los dos modelos de desarrollo señalados por la autora, cada uno con sus respectivas estrategias de inserción internacional, acabando por triunfar el binomio liberalismo/alineamiento, lo cual se vio rubricado con la firma del pacto Roca-Runciman y los alineamientos durante la Guerra del Chaco. Asimismo, las variaciones en la concepción de democracia, punto también mencionado por Busso, estuvieron presentes en la década de 1930 en la Argentina tras el primer golpe militar 
de su historia y la llegada al poder de Agustín P. Justo, especialmente tomando en consideración los métodos y prácticas políticas implementados durante los seis años de gobierno de este último.

Como consecuencia de lo hasta aquí señalado, se delineó un contexto político-económico interno en la Argentina que permite explicar parcialmente la posición del país ante la Guerra del Chaco, atendiendo a la premisa de que la política exterior de una nación, como ya se ha dicho y como sostienen Manfred Wilhelmy (1991) y María Natalia Tini (2005), entre otros, es una más de las distintas políticas públicas, resultante no sólo de la influencia de factores vinculados al contexto internacional imperante sino también, y principalmente, de la coyuntura política y económica interna, es decir, el modelo de desarrollo adoptado, con todo lo que ello implica: sus principales propulsores y beneficiarios, los intereses afectados, etc.

En consecuencia, el análisis de las variables internas que inciden en la formulación de la política exterior adquiere gran relevancia. Dentro de ellas, se destaca el tipo de régimen imperante, tal lo señalado por corrientes como el internacionalismo liberal y el institucionalismo internacional e incorporado en sus análisis por María N. Tini (2005), Rubén Perina (1988), Alberto van Klaveren (1985) y profundizado por Marcelo Lasagna (1995), quien coloca especial énfasis en el análisis de los principios constitutivos de ese régimen así como en la ideología del elenco gobernante y la coalición de intereses que lo sustenta, lo cual lo lleva a distinguir entre la conducta exterior de los regímenes democráticos y autoritarios: mientras éstos suelen tener una fuerte autonomía de la influencia popular y una autonomía débil de las élites, especialmente de grupos empresariales y/o militares cuya gravitación en las decisiones de política exterior es también señalada por autores como Eliana Calderón (2014) - , en el caso de los primeros se presenta generalmente la relación inversa.

Resulta evidente la pertinencia de este abordaje para el caso de estudio propuesto si se tiene en consideración, primero, que durante el gobierno militar de Uriburu se registró un alto grado de participación de las empresas extranjeras (como la petrolera norteamericana Standard Oil) en las decisiones gubernamentales, a partir de su presencia preponderante en el gabinete de ministros, ${ }^{2}$ lo cual se hace eco también de lo planteado por Alberto van

2 Según Mayo, Andino y García Molina, “nunca habían tenido las compañías voceros tan encumbrados y directos en las esferas gubernamentales argentinas como ahora. El gabinete de Uriburu parecía el directorio local de una empresa multinacional. Se daban 
Klaveren (1985), William Hazleton (1987) y Heraldo Muñoz (1987), quienes señalan como uno de los factores que inciden en la formulación de la política exterior a la actuación de empresas transnacionales y sus vínculos con actores locales. Asimismo, este enfoque que distingue entre regímenes militares y democráticos resulta particularmente útil a la hora de analizar el régimen justista, atendiendo a las peculiaridades del mismo: si bien durante su mandato se pretendieron respetar el republicanismo y la democracia, la falta de popularidad de muchas de sus medidas de gobierno — como la firma del Pacto Roca-Runciman con Gran Bretaña o la creación de la Corporación de Transportes - y su débil autonomía respecto de las élites económicas y militares (de las cuales el propio Presidente, de hecho, formaba parte), pondrían de manifiesto el carácter predominantemente autoritario (o, mejor, no democrático) de su gestión, lo cual se ve corroborado por algunas otras prácticas y disposiciones como el fraude electoral implementado a gran escala, la denegación de la legalidad al Partido Comunista, la conformación de grupos de choque con asentimiento del Poder Ejecutivo y la represión contra diversos sectores de la izquierda.

Ahora bien, yendo a la cuestión de la posición argentina ante la Guerra del Chaco, la permeabilidad del régimen justista a la influencia de empresarios y militares se puede advertir de forma evidente: consideraciones geopolíticas imperantes en el sector castrense preconizaban la alianza natural con Paraguay, la inconveniencia de que Bolivia fuese ribereña del río homónimo y el mantenimiento de una empresa petrolera estatal fuerte, atendiendo a una eventual conflagración contra el Brasil; ${ }^{3}$ cuestiones todas ellas que

cita en él representantes de los intereses económicos norteamericanos, alemanes y británicos operantes en el país” (Mayo, Andino y GarCía Molina, 1983: 157).

3 En una entrevista mantenida con Justo a fines de 1933, el Ministro paraguayo en Buenos Aires, Vicente Rivarola, le hizo notar al Presidente argentino estas mismas consideraciones: "Bolivia — dijo—, obteniendo una salida sobre el río Paraguay, lo primero que haría sería construir un puerto militar y hacerse de una marina de guerra (...). Tampoco le conviene a la Argentina para el caso de una guerra con el Brasil (...) desde que el Paraguay, aliado natural de la Argentina, hoy mucho más después de la ayuda de todo género que nos están prestando, (...) podría eliminar todo peligro por el lado del Estado de Mato Grosso, lo que no podría hacer teniendo Bolivia, aliada del Brasil, puerto y marina de guerra sobre el río Paraguay” (Carta de Vicente Rivarola a Eusebio Ayala, Buenos Aires, 25/11/1933, en Rivarola Coello, 1982: 215). Además, la eventual presencia boliviana sobre la costa del río Paraguay con ferrocarriles, puertos y buques que llevasen su bandera, empresas industriales y haciendas, podría tener consecuencias que modificarían el equilibrio de la política internacional en la cuenca del Plata (Brezzo, 2001). En este sentido, si Bolivia accedía al río Paraguay y lograba con- 
se vieron satisfechas mediante la intervención argentina en el conflicto y en las negociaciones de paz; mientras que, por su parte, también influyó la capacidad de lobby de los empresarios angloargentinos que operaban en el Chaco paraguayo —algunos de ellos vinculados por lazos comerciales y/o de parentesco al personal político y diplomático del gobierno de Justo e incluso al propio Presidente- ${ }^{4}$ incluidas aquellas firmas que, como la Carlos Casado o la Mihanovich, se beneficiaban de la explotación, comercialización y transporte del quebracho y del tanino procedentes de aquella región.

Tan gravitante llegó a ser esa influencia que llevaría al Poder Ejecutivo a violentar uno de los principios que la Argentina había históricamente sostenido - y aún seguía haciéndolo en cuanta conferencia panamericana a fin de cuestionar el accionar norteamericano y la Doctrina Monroe- referido a la no intervención en los asuntos internos de otro Estado, particularmente a través de la protección diplomática a los capitales nacionales invertidos en el exterior, tal como lo haría la administración justista en relación a aquellos operantes en el Chaco Boreal durante el transcurso de la guerra boliviano-paraguaya, lo cual se hizo evidente en ocasión del ata-

vertirlo en una vía para canalizar su producción, creando un área de influencia directa con la posibilidad de que se generara un polo demográfico importante, se podía llegar a producir una puja por la libre navegación de los ríos interiores, lo que sensibilizaba a la dirigencia argentina y especialmente a los militares (PÉREz STOCCO, 2012: 62-63), ya que conspiraba contra la intenciones de la dirigencia argentina de controlar el transporte de la producción del oriente boliviano, especialmente la petrolera, a través de territorio argentino y preferentemente vía ferrocarril. En este sentido, según informes del diplomático brasileño Orlando Leite Ribeiro, de servicio en Buenos Aires, la Argentina veía "con pavor” la salida de Bolivia por el río Paraguay, dado que inundaría el mercado con petróleo, "matando su reciente industria de Comodoro Rivadavia”. En su opinión, "la cuestión del petróleo es lo que más le interesa a la Argentina y de ahí el hecho de que ella nunca haya apoyado la pretensión justa de Bolivia de obtener una salida al río”. Además de lo señalado, un triunfo boliviano implicaría el arraigo de la Standard Oil en la región, amenazando el desarrollo de la Shell y, sobre todo, de YPF en las provincias del norte argentino, donde la firma norteamericana contaba con importantes apoyos, como el de Robustiano Patrón Costas (Moniz BANDEIRA, 2004: 148 y 161).

4 La familia Casado, radicada en Rosario y principal latifundista en el Chaco paraguayo, se hallaba vinculada a la dirigencia política argentina: por un lado, el Canciller Carlos Saavedra Lamas, antes de asumir ese cargo, fue abogado de la empresa, y durante su ministerio su estudio continuó atendiendo los asuntos legales de la misma; por otro, uno de los hijos de Carlos Casado — propietario original de la firma— poco después de la muerte de su padre contrajo matrimonio con la hermana del futuro Presidente Justo (DALLA CORTE, 2009). 
que a Puerto Casado, por ejemplo. ${ }^{5}$ Asimismo, la Argentina renunciaría a un segundo principio internacional por siempre sostenido - e incluso ratificado mediante el Pacto Antibélico de 1933 propuesto por el Canciller Carlos Saavedra Lamas a fin de evitar futuras guerras en el continente como la que se estaba desarrollando entre Bolivia y Paraguay y que lo haría acreedor del Premio Nobel de la Paz del año 1936 - a fin de asegurar los beneficios de estos empresarios y de satisfacer el interés nacional y militar evitando que Bolivia llegase a orillas del río Paraguay: se trata del reconocimiento, a través del laudo arbitral de 1938, de las adquisiciones

5 En abril de 1933, en plena Guerra del Chaco, la aviación boliviana atacó la localidad paraguaya de Puerto Casado, argumentando que la misma no era sólo parte de la infraestructura empresarial sino también "el corazón de la actividad bélica paraguaya” (DALLA CORTE, 2009: 454). Ante el hecho consumado, la Cancillería argentina envió una nota a la Legación de ese país en Buenos Aires, fechada el 29 de mayo de 1933, en la que, tras dar cuenta de lo sucedido y de los daños registrados, exponía: "Vuestra Excelencia no ignora que Puerto Casado es una población civil no defendida, en la cual funciona un establecimiento industrial de la Compañía Argentina Carlos Casado, destinado a la fabricación de tanino (...). Este Ministerio no puede admitir que los argentinos que se han radicado en el Chaco Boreal, transformando tierras antes inexplotadas en emporios de riqueza agrícola y comercial deban sufrir los excesos en que por error, por impericia o por extravío, puedan incurrir las fuerzas militares de un país beligerante. Estos sucesos, tan dolorosos como irrefutables, mueven a esta Cancillería a dirigirse a V. E. formalizando reclamación por los intereses argentinos afectados, cuya importancia y monto se fijará en su oportunidad, y haciendo presente que espera que el Gobierno de Bolivia se abstendrá de repetir tales hechos de hostilidad sobre poblaciones civiles, que de otro modo podrían herir fundamentalmente nuestras cordiales relaciones" (AyAla MorEIRA, 1959: 366-367). Otra prueba de la protección que el Gobierno de Justo brindó a los capitales argentinos en el Paraguay es la reclamación entablada por la Sociedad Anónima Domingo Barthe a causa de la ocupación de tierras de su propiedad por colonos rusos, establecidos con autorización y orden de las autoridades paraguayas. En la nota que la Cancillería argentina envió a mediados de 1934 a su Legación en Paraguay indicaba que, si bien dicha empresa antes de solicitar el amparo diplomático del Gobierno argentino debía demostrar que había agotado los recursos legales ante el Gobierno paraguayo, en conformidad con la tesis invariablemente sostenida por la Argentina en el ámbito del derecho internacional en ese sentido, se autorizaba al Ministro argentino en Asunción, Rodolfo Freyre, a realizar ante la Cancillería paraguaya, “en forma oficiosa y verbal, las gestiones que considere convenientes en apoyo de la reclamación” de Barthe [Carta del Canciller Carlos Saavedra Lamas al Enviado Extraordinario y Ministro Plenipotenciario argentino en Paraguay, Rodolfo Freyre, Buenos Aires, 6 de julio de 1934, en Archivo del Ministerio de Relaciones Exteriores y Culto (AMREC), División de política, Paraguay y otros, 1934]. De esta manera quedaba demostrada, por segunda vez durante la contienda del Chaco, la buena voluntad del Gobierno argentino para interceder en favor de los inversores nacionales instalados en Paraguay. 
territoriales paraguayas realizadas durante la campaña del Chaco, incluso habiendo alentado la toma de posesión de esas tierras por parte del Ejército paraguayo y su consiguiente reclamación en el transcurso de las negociaciones de paz.

Dentro de las variables internas también cabe situar, siguiendo a Robert Putnam (1988), Esteban Actis (2012), Rubén Perina (1988) y Roberto Russell (1990), a los diferentes actores — denominados "actores domésticos autónomos” por Pablo Valenzuela (2013) — que influyen o participan en la formulación y ejecución de la política exterior buscando imponer sus propias agendas e intereses, siempre teniendo en claro que la adopción de la decisión sólo puede ser realizada por actores gubernamentales domésticos, capacitados a comprometer los recursos de la sociedad. De ello se deriva la importancia de lo que Lasagna denomina "sociedad política" — partidos políticos, grupos de interés, grupos de presión-, tanto de aquellos que, como la UCR, actuaron desde la ilegalidad como de los que constituyeron la oposición parlamentaria y, fundamentalmente, los distintos sectores que componían la Concordancia, haciendo hincapié en determinadas figuras fuertes del régimen, como el Presidente Agustín P. Justo y Robustiano Patrón Costas, quienes en ocasiones, como en relación a la producción petrolífera de Salta y sus implicancias en relación a los vínculos con Estados Unidos y Gran Bretaña y la neutralidad argentina en la Guerra del Chaco, se encontraron enfrentados.

En esa ocasión pudo observarse, tal lo postulado por Helen Ingram y Suzanne Fiederlein (1988), la importancia de las provincias como entes intervinientes en el proceso de toma de decisiones en política exterior. La cuestión del petróleo salteño y el mayor o menor acercamiento que las autoridades de la provincia del norte coyunturalmente pudiesen experimentar en relación al Gobierno Nacional o a los intereses privados, marcaban el ritmo de la competencia entre YPF y la Standard Oil, empresa que desde sus campos petrolíferos en Bolivia esperaba contar con la aquiescencia de las autoridades argentinas para poder construir un oleoducto que le permitiese transportar el hidrocarburo hacia aguas abiertas en el Atlántico y que, al no encontrarla, habría estimulado a Bolivia a lanzarse contra el Paraguay por la posesión del Chaco Boreal. En virtud de lo señalado es que cobra trascendencia la figura de Robustiano Patrón Costas, figura emblemática de la Concordancia, Presidente del Senado de la Nación durante el sexenio de gobierno justista y empresario azucarero salteño vinculado a inversiones norteamericanas, que en alguna medida condicionó al gobierno de Justo, ya sea brindándole o insinuando con retirarle su apoyo, cuando aquél debía 
negociar el tratado Roca-Runciman en el contexto de una guerra ya iniciada en el Chaco en la cual también estaban en juego importantes intereses nacionales y privados.

De lo anterior se desprende, asimismo, la existencia de pugnas personales hacia el interior de la propia élite gobernante, en este caso sustentadas en distintas percepciones e intereses de los actores, tal como propone Russell (1990). Pero más allá de la disputa Justo-Patrón Costas, cabe dar cuenta de otros enfrentamientos presentes durante todo el proceso de guerra y negociaciones en el Chaco, si bien su influencia debe ser minimizada, pues no representan intereses permanentes sino que más bien responden a querellas circunstanciales, las cuales, no obstante, tienen la capacidad de predisponer, en un sentido u otro, a los negociadores. Dentro de este punto pueden ser mencionados los conflictos existentes dentro del grupo mediador, destacándose aquellas en torno al Canciller argentino Carlos Saavedra Lamas: con el Secretario de Estado norteamericano Cordell Hull, con sucesivos ministros y/o representantes brasileños y bolivianos, con el delegado norteamericano a la Conferencia de Paz Spruille Braden, con el Canciller chileno Cruchaga Tocornal y ocasionalmente con algún representante paraguayo. ${ }^{6}$

Asimismo, se observaron enfrentamientos y divergencias hacia el interior de la coalición gobernante en Argentina, incluso dentro del propio gabinete nacional: Saavedra Lamas y el Ministro de Guerra, Manuel Rodríguez, confrontaron en más de una ocasión en relación a la ayuda que se estaba prestando al Paraguay durante la guerra; ${ }^{7}$ mientras que el primero de ellos

6 El Presidente paraguayo, Eusebio Ayala, aseguraba tener pruebas del "mal espíritu” de Cruchaga Tocornal contra Saavedra Lamas (Cartas de Eusebio Ayala a Vicente Rivarola, Asunción, 23/02/1935 y 03/04/1935, en RivAROLA CoELLO, 1982: 293 y 298), mientras que en cuanto a Hull, siempre existieron rispideces y se profesaban un indisimulado fastidio mutuo con el Canciller argentino. Sin embargo, la disputa más importante se daba entre éste último y Braden. En su autobiografía, éste sostenía: “es generalmente sabido que Carlos Saavedra Lamas, el desmesuradamente egoísta Ministro de Relaciones Exteriores argentino, quería provocar la mayor cantidad de problemas posibles para los EE.UU. No había nadie entre los latinoamericanos que tuviera dudas acerca de que Saavedra Lamas retrasaría la paz, hasta que todo el mundo supiera que era él el hacedor de la misma. La entrega del Premio Nobel a Saavedra Lamas fue un gran disgusto para mí (...). Era vanidoso, patológicamente ambicioso, esencialmente un estúpido y un mal hombre” (FrAGA, 1991: 30).

7 Según los relatos del representante paraguayo en Buenos Aires, Vicente Rivarola, durante los primeros meses de la Guerra del Chaco el Canciller argentino ignoraba que, a 
parecía también tener diferencias de criterio con un hombre influyente del régimen como Robustiano Patrón Costas en virtud de sus preferencias internacionales (éste último vinculado a los Estados Unidos, siendo aquél antinorteamericano y proeuropeo), llegando incluso a maniobrar en detrimento de sus intereses, como cuando promovió una ley contra el monopolio azucarero. ${ }^{8}$ Hay que tener en cuenta que estos tres actores políticos tenían aspiraciones presidenciales de cara a las elecciones de 1937, lo cual podría eventualmente haber incrementado las rispideces entre ellos o favorecido su intención de adquirir mayor notoriedad diferenciándose unos de otros, a fin de capitalizarlo políticamente.

De igual modo, siguiendo este enfoque, y particularmente la propuesta de Rapoport y Spiguel (2005) cuando sostienen que para explicar la política exterior argentina es necesario analizar su estrecha vinculación con la naturaleza sociohistórica del Estado y con la estructura económica de la sociedad, se considera relevante el papel desempeñado por aquellos actores económicamente poderosos y políticamente influyentes que incidieron en las decisiones de política exterior, como el caso de la Sociedad Rural Argentina (SRA), muchos de cuyos miembros eran parte del elenco gobernante nucleado en el Partido Demócrata Nacional y en el radicalismo antipersonalista. ${ }^{9}$ De esta manera, los intereses político-económicos que sustentaban

través de los ministerios de Guerra y Marina, se estaba proveyendo de material bélico a Paraguay, comprometiendo la neutralidad argentina en el conflicto, la cual era indispensable aparentar para llevar a buen término las negociaciones que el propio Saavedra Lamas promovía. Ello motivó enfrentamientos en el seno del gabinete nacional, como el de marzo de 1934, en el cual Rivarola intervino buscando indisponer al Ministro Rodríguez contra el Canciller, a sabiendas de su influencia sobre el Presidente, "un poco con la esperanza de provocar el retiro del gabinete del doctor Saavedra Lamas, que yo conceptúo pueda ser beneficioso para nuestras gestiones diplomáticas” (Carta de Vicente Rivarola a Eusebio Ayala, Buenos Aires, 30/03/1934, en Rivarola Coello, 1982: 235-236). Sin embargo, tras la intervención de Justo, el asunto se zanjó sin ulteriores consecuencias.

8 Se trata de un proyecto estableciendo medidas proteccionistas, el cual fue promovido por Saavedra Lamas en 1912, cuando éste se desempeñaba como Diputado Nacional, y que acabaría convirtiéndose en la ley No 8.873 (Olmos GAONA, “Inédito”).

9 Tal grado de influencia no se explica a partir del peso numérico de dicha institución [según datos de Peter Smith (1968) el total de socios de la SRA hacia la década de 1930 oscilaba en torno a los 2.500, y del censo de 1937 surge que sólo nucleaba a un $1 \%$ del total de propietarios de ganado del país], sino del alcance nacional de la misma —que contaba con sedes en diversos pueblos y ciudades del interior del país- y, fundamentalmente, de la posición económica y políticamente dominante de sus miembros. De hecho, tanto el propio Presidente Justo como el Vicepresidente Julio A. Roca (hijo) eran miem- 
al régimen [lo que Ingram y Fiederlein (1988) identifican como "determinados grupos de interés” y cuyo número y complejidad, siguiendo a van Klaveren (1985), tiende a ser mayor en países relativamente grandes y desarrollados como la Argentina] se confundían con el régimen mismo, otorgándole una gran solidez y clara conciencia de sus objetivos, lo cual se veía proyectado en una política exterior coherente y tendiente a satisfacer esos intereses comunes, fundamentalmente mediante la asociación con Gran Bretaña pero también a través de la oposición a Estados Unidos y la defensa de sus posiciones en el Paraguay. Esto, a su vez, se vincula a lo señalado por Robert Keohane y Joseph Nye (1988), cuando destacan no sólo la influencia en la confección de políticas por parte de determinados grupos de interés sino, más aún, la capacidad de estos para operar en forma coordinada con sus contrapartes en el exterior.

En relación a esto último, otra de las variables propuestas por Perina (1988) resulta fundamental. Se trata de la capacidad económica, políticoinstitucional, tecnológica, militar y diplomática [el servicio diplomático profesional al que se refiere Hugo Dalbosco (2014), conformado principalmente por miembros de la élite ${ }^{10}$ del Estado, representada por los re-

bros de la Sociedad Rural, mientras que el gabinete de su gobierno estaba compuesto por seis “aristócratas" tradicionales, tres de los cuales también pertenecían a dicha institución, formando asimismo parte de ella numerosos legisladores oficialistas (Smith, 1968).

10 Tomando algunos indicadores propuestos en el modelo prosopográfico desarrollado por Lawrence Stone (1986) aplicados a los cancilleres y ministros argentinos en Bolivia y Paraguay entre 1920 y 1940, se constata que el 69,2 \% de los cancilleres fueron bonaerenses (Capital o Provincia), mientras que el 66,6 \% de los representantes en Bolivia y Paraguay provenían del interior del país. En cuanto a la pertenencia o no de dichos funcionarios a la SRA, sobre un total de doce cancilleres en el periodo mencionado, al menos siete, es decir el 58,3 \%, fueron miembros de la Sociedad Rural, no habiéndose recabado datos suficientes en relación al otro grupo para este punto. En cuanto a las profesiones y estudios universitarios, tanto el perfil de los cancilleres como de los diplomáticos acreditados en Paraguay y Bolivia es coincidente: no sólo 22 de los 23 individuos analizados poseían estudios superiores, sino que, sobre ese total, 20, es decir el $87 \%$, cursaron estudios de derecho. Ahora bien, si al dato anterior se lo cruza con la variable referida a la universidad donde cada funcionario estudió, se advierte que, de los 22 que tenían algún tipo de formación superior, al menos 15 (68,2 \%) lo hizo en la Universidad de Buenos Aires, y 14 de ellos en la Facultad de Derecho. La cifra proporcionada es contundente, y más aún si se desagrega el caso de los cancilleres, ya que 11 de un total de 13 estudiaron en la mencionada universidad, diez de ellos en la Facultad de Derecho. De esta manera, al menos el 60,9 \% del total de los funcionarios analizados estudió en dicha 
cursos o instrumentos con que cuentan los responsables de la política exterior para lograr sus objetivos. En virtud de ello, precisamente, es que Argentina (sus clases dirigentes y socioeconómicamente dominantes), en una posición de superioridad o dominio en relación a Paraguay pero de inferioridad o dependencia respecto de Gran Bretaña, desarrolló un patrón de conducta internacional acorde a esa situación, determinando así los alineamientos durante la Guerra del Chaco. Idéntica situación ocurrió para el eje Estados Unidos-Brasil-Bolivia, aunque esto escapa al interés de este trabajo.

También dentro de las variables internas se encuentra lo que Rubén Perina (1988) denomina "cultura política" de los actores y que asimismo otros autores como Russell (1990), Tini (2005) y Lasagna (1995) consideran como factor explicativo de la conducta exterior de los Estados. Implica incorporar en el análisis, a través de la utilización del método prosopográfi-

facultad, ascendiendo el porcentaje al 76,9 \% para el caso específico de los cancilleres. En esta misma línea, sumando la información obtenida en ambos grupos, se puede afirmar que el 69,6 \% pertenecía a familias de élite, emparentadas o vinculadas a ella, mientras que, en contrapartida, de sólo dos de los 23 individuos que componen el universo de estudio (8,3\%) se puede aseverar que procedían de familias de origen humilde. Como último punto, tras estudiar todos los casos, la tendencia demuestra que se solía privilegiar el hecho de que el "candidato" contara con una importante trayectoria política previa para llegar al puesto de Canciller, mientras que para acceder al de Enviado Extraordinario y Ministro Plenipotenciario, en este caso en Bolivia o en Paraguay, era menester contar con cierta experiencia en el campo diplomático. En definitiva, puede concluirse que poseer un título universitario, especialmente el de abogado egresado de la Facultad de Derecho de la Universidad de Buenos Aires y pertenecer a una familia "notable” o "tradicional” constituían aspectos que favorecían el ingreso a la estructura del Ministerio de Relaciones Exteriores para los cargos estudiados entre 1920 y 1940; así como ser miembro de la Sociedad Rural Argentina, haber nacido en Buenos Aires (capital o provincia) y contar con experiencia política previa incrementaban las posibilidades de ser Canciller, mientras que, por el contrario, provenir del interior del país y poseer cierta trayectoria en el ámbito diplomático se advierte como una variable más continua para ocupar el cargo de Ministro en Bolivia o Paraguay. Por lo tanto, y en virtud especialmente de los primeros tres aspectos señalados, es posible afirmar que, a partir de una cuidadosa selección de sus miembros, el Ministerio de Relaciones Exteriores exigía una determinada calificación profesional y político-diplomática — vinculada a factores de origen y estatus social - en sus filas, no sólo para su cabeza principal y más visible (el Canciller) sino también, en este caso concreto, para sus delegados en dos países vecinos en un momento crítico, tanto de sus respectivas historias nacionales como para la estabilidad de la región en su conjunto (AMREC, Dirección de Legajos de Personal). 
co desarrollado por Lawrence Stone (1986), aquellos valores, actitudes, creencias, tradiciones, hábitos, ideas e ideología que hacen de la clase dirigente un grupo cohesionado y consciente de sus metas e intereses. Esto - también señalado por Mauricio Alice (2009) al remarcar la importancia de tener en cuenta el perfil de los encargados de ejecutar la política exterior - resulta clave si se tiene en cuenta que una de las principales cuestiones a considerar a la hora de entender la actuación argentina ante el conflicto chaqueño es la visión que del país y del mundo tenían los círculos gobernantes y aquellos sectores directamente vinculados a la formulación y ejecución de la política exterior, lo cual transformaría a la misma en un instrumento de la clase dominante, tal y como lo plantea la teoría estructuralista.

Esa concepción, que se enmarca dentro de una "tradición histórica" -apelando a uno de los factores internos enunciados por van Klaveren (1985) — caracterizada por un fuerte contenido de superioridad moral y búsqueda de reconocimiento y prestigio internacional, ubicaba al país en un rol preponderante en los asuntos hemisféricos, directivo en relación a las naciones latinoamericanas, y absorbente hacia los pequeños países vinculados a la cuenca del Plata. Esta autopercepción de la Argentina y su clase dirigente se vería plasmada, al igual que en las sucesivas conferencias panamericanas desde 1889, en la Guerra del Chaco, conduciendo a una confrontación por el liderazgo de las negociaciones de paz con los Estados Unidos primero y con el Brasil después; y obtuvo uno de sus relieves más notorios con el otorgamiento del Premio Nobel de la Paz al Canciller Saavedra Lamas.

Se comprende así, pues, que para viabilizar esa confrontación con los Estados Unidos, la dirigencia argentina se apoyase en su histórica aliada comercial: Europa, y dentro de ella muy especialmente en Gran Bretaña, que no sólo contaba con influyentes voceros e inversiones en el país sino que compartía también intereses en el Chaco paraguayo. ${ }^{11}$ De esta mane-

11 Desde la inmediata posguerra de la Triple Alianza (1865-1870) los capitales angloargentinos irrumpieron en la economía paraguaya. Hacia 1910, existían numerosas compañías de tierras e hipotecarias británicas, radicadas en Argentina pero con intereses en Paraguay, entre las que se destacan The Argentine Quebracho Co.; The Argentine Land \& Investment Co. Ld.; la Santa Fe \& Córdoba Great Southern Land Co. Ld.; y The Forestal Land, Timber \& Hailways Co. Ld (La Forestal). Asimismo, la compañía inglesa Liebig's ingresó en el Chaco paraguayo en 1898 y hacia el año 1911 adquirió un total de 93.744 ha., siendo uno de sus primeros directores el Barón de Mauá (de 
ra, la apelación a la Liga de las Naciones —organización eminentemente europea a la que Argentina se reincorporó bajo la Presidencia de Justo y de la que no formaban parte ni Brasil ni los Estados Unidos- como foro para solucionar la disputa boliviano-paraguaya primero y los intentos, finalmente exitosos, de liderar las negociaciones de paz después; la defensa de las inversiones angloargentinas en el Chaco y la existencia de un competidor común (para YPF y la Royal Dutch-Shell) como la Standard Oil norteamericana, constituían todos ellos factores confluyentes que modelaron la actuación argentina ante el conflicto, orientándolo en una dirección bien definida: incrementar el prestigio internacional del país en detrimento del panamericanismo sustentado por los Estados Unidos y mantener los beneficios de una asociación lucrativa para los sectores económica y políticamente dominantes, al tiempo que se resguardaban los intereses de la empresa petrolera estatal — caros al pensamiento geopolítico y militar del contexto- y de los inversores angloargentinos instalados en el Chaco Boreal.

Otra de las variables internas influyentes en la formulación de la política exterior, siguiendo principalmente a Leandro Sánchez (2013) pero también a María N. Tini (2005), Esteban Actis (2012) e Ingram y Fiederlein (1988), es el Poder Legislativo Nacional. Este enfoque, al subrayar la importancia del Congreso Nacional en las decisiones de política exterior, permite dar cuenta desde el tratamiento del ingreso del país a la Sociedad de las Nacio-

la London Brazilian y Mauá's Bank), quien estaba estrechamente vinculado a Carlos Casado desde el momento en que instaló su sucursal bancaria en Rosario en la década de 1860. A esta lista habría que sumar a La Industrial Paraguaya, empresa de capitales angloargentinos instalada en 1886 y dedicada a la producción de yerba mate, la cual contaba con gran poder e influencia en Paraguay, donde poseía 868.125 ha de tierras, pero en la región oriental del país (DALla CoRTE, 2009). De este modo, ya en vísperas de la Primera Guerra Mundial, 68 compañías de ese origen poseían 10 millones de hectáreas en el Chaco Boreal dedicadas a la explotación ganadera y maderera (SoLVEIRA, 1995), y se calcula que hacia fines de la década de 1930 el $30 \%$ del capital extranjero invertido en el Paraguay era argentino y el 25 \% británico (CEPAL, 1987). Además, en la navegación fluvial predominaba, por el tonelaje de las mercaderías transportadas, la Compañía Argentina de Navegación Mihanovich. A esto hay que añadir la influencia ejercida por el sector de la banca rioplatense (Tornquist, Casado, Pinasco, Born, Bunge y Mihanovich), los cuales se hallaban estrechamente relacionados a los intereses de los empresarios (PÉrez Stocco, 2012), y el hecho de que también capitales porteños controlaban el transporte ferroviario desde y hacia Paraguay a través del Ferrocarril Central, cuyo tendido corría en un 65 \% por territorio argentino (Figallo, 1997). 
nes en plena guerra en el Chaco ${ }^{12}$ hasta la ratificación de los tratados de límites con Bolivia (1927), Paraguay (1939) y Brasil (1940), ${ }^{13}$ pasando por el debate en torno al Pacto Roca-Runciman ${ }^{14}$ y el Pacto Antibélico, ${ }^{15}$ cuestiones todas ellas que, directa o indirectamente, afectaron las decisiones en la materia en general y en relación a la posición del país ante el conflicto del Chaco en particular.

Marcelo Lasagna (1995), Mauricio Alice (2009), Ingram y Fiederlein (1988) y Pierre Renouvin (2000) —este último al incorporarlos dentro de su análisis de las "fuerzas profundas" a partir de lo que denomina "mentalidad colectiva"-, por su parte, ponen de relieve la influencia que los grupos de interés, la opinión pública y los medios de comunicación ejercen en el proceso de formulación de la política exterior. Mientras que en relación a los primeros ya se ha visto su injerencia, en lo que hace a la opinión pública cabe mencionar que la misma también jugó un rol de importancia, colocándose en forma casi unánime en favor de la causa paraguaya y manifestando indiferencia y hasta cierta hostilidad hacia Bolivia, en parte

12 Para profundizar sobre esta cuestión se sugiere consultar: CÁMARA DE DiPUTADOS DE LA NACIÓn, Diario de Sesiones, 27 y 28 de septiembre de 1932, pp. 779-820 y CÁmara de Senadores de la Nación, Diario de Sesiones, 25 de septiembre de 1933: 422-460.

13 En el caso de Bolivia, la demarcación definitiva fue concluida en 1925 tras la firma del tratado Carrillo-Diez de Medina, efectuándose el tratamiento legislativo correspondiente en Argentina mediante sesiones secretas de la Cámara de Senadores, en julio de 1927 (CÁmara de Senadores de la Nación, Diario de Sesiones, 21 de julio de 1927, pp. 258). En cuanto al Paraguay, la negociación se dio en plenas tratativas por la paz del Chaco en Buenos Aires, lo cual generó rispideces en ambas partes (CÁMARA DE SENADORES DE LA NACIÓN, Diario de Sesiones, 22 de septiembre de 1939, pp. 480-504). En relación a las alternativas y debates en torno al tratado con Brasil, ver CÁMARA DE SENADORES DE LA NACIÓn, Diario de Sesiones, 8 de agosto de 1940, pp. 307-308 y 810-812; y Cámara de Diputados de la Nación, Diario de Sesiones, 6 de septiembre de 1940, pp. 946-951.

14 Ver Cámara de Diputados de la Nación, Diario de Sesiones, 18 y 19 de julio de 1933, pp. 285-374, y CÁmARa de SenAdores de la NACión, Diario de Sesiones, 27 y 28 de julio de 1933, pp. 568-615.

15 La ratificación por parte del Poder Legislativo se efectuó los días 27 y 30 de septiembre de 1935, siendo el Pacto presentado por el bloque oficialista como parte de un continuum en la tradición jurídica internacional del país, al afirmar el Diputado Escobar que el mismo significaba la concreción de "los ideales de paz y justicia que siempre ha sostenido en la vida internacional la República Argentina” (CÁMARA DE DiPUTADOs DE LA NACIÓn, Diario de Sesiones, 27 de septiembre de 1935, pp. 642-661; y CÁMARA DE SENADORES DE LA NACión, Diario de Sesiones, 30 de septiembre de 1935, pp. 802-818). 
posiblemente influida por la campaña abiertamente proparaguaya que llevaron adelante la mayor parte de los medios de comunicación nacionales en la Argentina. ${ }^{16}$

Por último, resta destacar también la incidencia que tuvieron en la formulación de la política exterior argentina en torno al conflicto chaqueño — tal lo sostenido por William Hazleton (1987), Heraldo Muñoz (1987) y Alberto van Klaveren (1985) - la teoría realista de poder (o política de poder) y las percepciones o imágenes sobre el sistema internacional, la potencia hegemónica de turno y los Estados vecinos. En cuanto a lo primero, siguiendo fundamentalmente lo desarrollado por el último de los autores mencionados, contribuye a explicar el patrón de comportamiento de la Argentina y Brasil, tanto en relación a Bolivia y Paraguay penetran-

16 Esto se debió en parte a la campaña emprendida por el ministro paraguayo en Buenos Aires. Los periódicos La Razón, La Nación, La Prensa, Crítica, Tribuna Libre y Noticias Gráficas fueron visitados por Rivarola, quien se aseguró su apoyo a la causa paraguaya (Carta de Vicente Rivarola a Eusebio Ayala, Buenos Aires, 30/07/1932, en Rivarola Coello, 1982). En cuanto a La Razón, uno de sus directores, el Dr. Ángel Sojo, puso a disposición de Rivarola sus páginas para la defensa del Paraguay (Peña Villamil, 1994), mientras que el corresponsal enviado por este periódico a cubrir la guerra, Manuel María Oliver, era presentado y encomendado al comandante en jefe de las fuerzas paraguayas, José F. Estigarribia, por el Presidente paraguayo, quien lo referenció como amigo personal y "buen amigo del Paraguay”. En el caso de La Nación, los artículos sobre la Guerra del Chaco corrían por cuenta de Podestá Costa, asesor jurídico de la Cancillería argentina, hombre "decididamente bien dispuesto a nuestro favor”, según palabras de Rivarola (Carta de Vicente Rivarola a Eusbio Ayala, Buenos Aires, 01/09/1932, en Rivarola Coello, 1982: 94). Asimismo, el mencionado diplomático paraguayo afirmaba haber conversado con el director de La Prensa, Gainza Paz, quien le había referido que rechazó, sin leerlo, un artículo enviado por el representante boliviano en Buenos Aires (“Carta de Vicente Rivarola a Eusebio Ayala”, Buenos Aires, 02/08/1932, en Rivarola CoEllo, 1982). Simultáneamente, el fervor popular argentino se manifestaba en igual sentido. En este contexto es que se enmarca la constitución, el 30 de julio de 1932, del Comité Paraguayo de Buenos Aires, a invitación del Ministro Rivarola, que significó el punto de partida de una gran movilización, especialmente en la Capital Federal, a favor de la causa nacional paraguaya. Este tipo de manifestaciones llevarían a Rivarola a afirmar, en carta a su Presidente, que "es efectivamente admirable la espontaneidad y entusiasmo con que este pueblo, al parecer frío e indiferente, se ha solidarizado y se solidariza con la causa paraguaya. (...) Su sociedad sigue con cariño el desarrollo de los acontecimientos, gozando con nuestros triunfos, como si fueran propios, y su clase humilde siente el orgullo del heroísmo de nuestros soldados (...). Jamás ningún país habráse visto más huérfano de opinión como Bolivia en la actual contienda (Carta de Vicente Rivarola a Eusebio Ayala, Buenos Aires, 18/11/1931, en Rivarola Coello, 1982: 133-134). 
do en sus sistemas económicos y políticos de modo sistemático, como en sus relaciones bilaterales, rivalizando por el predominio en la Cuenca del Plata antes, durante y después de la Guerra del Chaco, llevándolos a adoptar posiciones internacionales divergentes en torno a la misma en procura de defender los intereses que uno y otro tenían en ambos contendientes.

Lo anterior se vincula estrechamente a las percepciones o imágenes sobre el sistema internacional, la potencia hegemónica de turno y los Estados vecinos que, en este caso, predominaban en la Argentina de los años 30, y que influenciaron decisivamente su accionar en el marco de la Guerra del Chaco: una Bolivia poco confiable e históricamente probrasileña; un Paraguay "aliado natural" ante una eventual conflagración y considerado prácticamente un prolongamiento territorial, político y económico; los Estados Unidos como agresiva potencia en ascenso y avasalladora de la soberanía de los países latinoamericanos; un Brasil considerado como principal rival en la región, siempre deseoso de incrementar su patrimonio territorial a expensas de sus vecinos y eventual enemigo en una contienda bélica por la supremacía en la cuenca del Plata; y finalmente Gran Bretaña, socio comercial por excelencia. De igual modo, las percepciones de otros países, como Estados Unidos, que veía en la Argentina un potencial competidor por el predominio hemisférico, ${ }^{17}$ o Brasil, que intuía en ese país una perenne voluntad de reconstruir la unidad política del antiguo Virreinato del Río de la Plata, ${ }^{18}$ también deben ser tenidas en cuenta a la hora de com-

17 Al respecto Lord Inverchapel, Embajador británico en Estados Unidos (1947) sostuvo que: "Durante cuarenta años o más, la Argentina ha sido una espina en la carne de sucesivos gobiernos norteamericanos, en razón de haber liderado continuamente la resistencia latinoamericana a la hegemonía de los Estados Unidos sobre el hemisferio occidental. Tanto los liberales argentinos — entre ellos, el doctor Saavedra Lamas - como los nacionalistas y militaristas, han exasperado a los estadistas norteamericanos con su pretensión de ser la voz de América Latina contra la dominación ‘yanqui' o la 'diplomacia del dólar'. Su exasperación durante años recientes ha sido acompañada por la incómoda conciencia de que la Argentina representa más que un desafío transitorio, y que otros países latinoamericanos, aunque inclinados a sospechar de la Argentina como de un trepador arrogante, a pesar de todo la consideran una bienvenida punta de lanza contra la penetración norteamericana” (EsCUDÉ, 1983: 50-51).

18 El barón de Cotegipe llegó a afirmar que "la reconstrucción del Virreinato está en los libros azules y en las verdes esperanzas del pueblo argentino (...) (el cual) tiene la ambición de querer hacer la primera figura en la América del Sud” (Etchepareborda, 1978: 62). También la prensa brasileña recelaba del expansionismo argentino; el Jor- 
prender los alineamientos internacionales en torno al conflicto por el Chaco Boreal.

\section{Reflexiones finales}

Durante el conflicto por el Chaco Boreal entre Bolivia y Paraguay, la Argentina, a la vez que se presentaba ante el mundo, desde el plano político diplomático como principal país mediador entre los contendientes, contribuyó de forma efectiva, desde el plano económico y militar, al triunfo de la causa paraguaya. Tal actitud respondía de forma integral a los intereses de Estado del país del Plata así como a los de la clase económicamente dominante que se hallaba a cargo del mismo y/o ejercía una influencia directa sobre el gobierno: le permitía mantener sus posiciones en el Paraguay, estrechar su lucrativa asociación con Gran Bretaña y oponerse a un enemigo común e histórico rival por la influencia política, diplomática y moral en el hemisferio: Estados Unidos y, junto con él, la Standard Oil. Es aquí donde se advierten más claramente, asimismo, los intereses de Estado involucrados, representados por la empresa petrolera estatal argentina, YPF, y también por influyentes sectores castrenses, que atendiendo a consideraciones geoestratégicas abogaban por el triunfo del Paraguay en detrimento no sólo de Bolivia, sino también del Brasil.

De esta manera, queda claro que el comportamiento externo de la Argentina en la coyuntura descripta respondió a factores preponderantemente internos. En consecuencia, teniendo en cuenta los aportes teóricos planteados al comienzo del presente trabajo, y tras su constatación a partir del estudio de caso propuesto, puede sostenerse que la política exterior debe ser considerada una más de las múltiples políticas públicas a través de la cual se

nal do Commercio publicó un artículo en el que sostenía que "son los Estados Unidos del Sur, en proyecto, más audaces y ambiciosos que los Estados Unidos del Norte” (Pomer, 1984: 258). Asimismo, el capitán brasileño Mário Travassos, cuya obra influyó en las élites brasileñas de los años 30 del siglo pasado que, directa o indirectamente, decidían los rumbos de la política exterior del país, llegó a afirmar: "la magnífica expansión del estado argentino, que cada vez más consolida la irradiación incomparable de su influencia, a la sombra de una misma lengua, de una misma religión y de la continuidad territorial que inspiraron los antiguos virreinatos, es más que un ejemplo, pues es una verdadera lección. El estado argentino, con el desarrollo de las comunicaciones, demuestra la más completa comprensión de su destino geopolítico” (PARADIso, 1993: 80). 
busca satisfacer tanto los intereses internos del Estado como los de la clase dirigente que coyunturalmente se encuentre en ejercicio del gobierno, siendo ésta la resultante de una combinación de variables tanto internas, propias del modelo de desarrollo político-económico, como externas, en función del contexto internacional y hemisférico imperantes, con una injerencia preponderante de las primeras.

En relación a esta concepción es que surge la necesidad de ampliar el espectro teórico en los estudios de política exterior y desarrollar nuevos marcos y herramientas para analizar esta última, a partir de incorporar elementos para la construcción de una perspectiva que profundice en la incidencia de las variables internas - cuya importancia ha quedado demostrada a pesar de haber sido históricamente soslayada en favor de los factores internacionales- en la formulación de la política exterior de los Estados en general y de la Argentina en particular. La presente investigación ha pretendido ser, pues, un modesto aporte en ese sentido.

\section{Bibliografía}

Actis, E. (2012). “Los condicionantes domésticos en los diseños de política exterior: la internacionalización de capitales brasileños como nuevo objetivo de la política exterior de Brasil”, Brazilian Journal of International Relations, volumen 1 (número 3), septiembre-diciembre de 2012, pp. 399-423.

Alice, M. (2009). El funcionamiento del proceso de toma de decisiones y las características del negociador argentino. Serie de artículos y testimonios, número 55. Consejo Argentino para las Relaciones Internacionales.

Ayala Moreira, R. (1959). Por qué no ganamos la guerra del chaco. La Paz: Talleres gráficos bolivianos.

Brezzo, L. (2001). “Argentina y Paraguay: de la hegemonía a la política pendular. Argentina y el plan de defensa paraguayo: cooperación militar e "intelligentsia” nacional”, XXIII International Congress Session. Washington: Latin American Studies Association, 6 al 8 de septiembre de 2001.

Busso, A. (2014). "Los vaivenes de la política exterior argentina re-democratizada (1983-2013). Reflexiones sobre el impacto de los condicionantes internos”, Estudios Internacionales, volumen 46 (número 177), enero de 2014, pp. 9-33.

CALDERón, E. E. (2014). "Variables domésticas y política exterior: el condicionamiento del contexto interno brasileño sobre las políticas de seguridad en la frontera con Colombia”, Relaciones Internacionales, volumen 23 (número 47), diciembre de 2014, pp. 67-86.

Dalbosco, H. L. (2014). Los Diplomáticos de Carrera y la Formulación de la Política Exterior Argentina (1983-2007). Buenos Aires-Argentina: Instituto de Ciencias Polí- 
ticas y Relaciones Internacionales, Facultad de Ciencias Sociales, Políticas y de la Comunicación, Pontificia Universidad Católica Argentina. Tesis de Doctorado en Ciencias Políticas.

DAlla CoRTe, G. (2009). Lealtades firmes. Redes de sociabilidad y empresas: la Carlos Casado S.A. entre la Argentina y el chaco paraguayo (1860-1940). Madrid: Consejo Superior de Investigaciones Científicas.

EscudÉ, C. (1983). Gran Bretaña, Estados Unidos y la declinación argentina 19421949. Buenos Aires: Editorial de Belgrano.

EtCHEPAREBORDA, R. (1978). Historia de las relaciones internacionales argentinas. Buenos Aires: Pleamar.

FABANI, O. (2016). “Condicionantes domésticos, regionales e internacionales y su incidencia sobre la política exterior de Bahrein tras los levantamientos en el mundo árabe”, Brazilian Journal of International Relations, volumen 5 (número 3), septiembre-diciembre 2016, pp. 518-544.

Figallo, B. (1997). "La Argentina frente a la rivalidad boliviano-paraguaya. Relaciones internacionales y estrategias económicas, 1920-1945”, Jornadas Internacionales “La Argentina y el mundo del siglo XX”. Bahía Blanca: Centro de estudios del siglo XX, Departamento de Humanidades, Universidad Nacional del Sur, 12 al 14 de noviembre de 1997.

Fraga, R. (1991). Carlos Saavedra Lamas. Estudio Preliminar. Buenos Aires: Centro de Estudios Unión para la Nueva Mayoría.

Gourevitch, P. (2007). “La 'segunda imagen’ invertida: los orígenes internacionales de las políticas domésticas”. En AcuÑA, C. (comp.). Lecturas sobre el Estado y las políticas públicas: Retomando el debate de ayer para fortalecer el actual. Buenos Aires: Proyecto de Modernización del Estado, pp. 473-504.

Hazleton, W. (1987). "Los procesos de decisión y las políticas exteriores”. En M. WILHELMY (ed.) La formación de la política exterior. Los países desarrollados y América Latina. Buenos Aires: Grupo Editor Latinoamericano, pp. 176-193.

INGRAM, H. y FIEDERLEIN, S. (1988). “Traversing boundaries: a public policy approach to the analysis of foreign policy”, The Western Political Quarterly, volumen 41 (número 4), diciembre 1988, pp. 725-745.

Keohane, R. y Nye, J. (1988). Poder e interdependencia: la política mundial en transición. Buenos Aires: Grupo Editorial Latinoamericano.

LASAgnA, M. (1995). “Las determinaciones internas de la política exterior: un tema descuidado en la teoría de la política exterior” Estudios Internacionales, año 28 (número 111), julio-setiembre 1995, pp. 387-409.

Macor, D. (2001). "Partidos, coaliciones y sistemas de poder”. En Cattaruzza, A. (dir.). Nueva Historia Argentina, Tomo VII, Crisis económica, avance del Estado e incertidumbre política (1930-1943). Buenos Aires: Sudamericana, pp. 49-96.

Mayo, C.; Andino, O. y García Molina, F. (1983). La diplomacia del petróleo: 19161930. Buenos Aires: Centro Editor de América Latina. 
Miranda, R. (2011). “Una clave en el análisis de la política exterior argentina: su sustentabilidad”. En Miranda, R. (comp.) y otros. Política exterior: conceptos y enfoques en torno a Argentina. Rosario: Pía, pp. 9-47.

Moniz Bandeira, L. A.(2004). Argentina, Brasil y Estados Unidos. De la Triple Alianza al Mercosur. Conflicto e integración en América del Sur. Buenos Aires: Norma.

MuÑoz, H. (1987). "El estudio de las políticas exteriores latinoamericanas: temas y enfoques dominantes”. En Wilhelmy, M. (ed.). La formación de la Política Exterior. Buenos Aires: Grupo Editor Latinoamericano, pp. 287-316.

Olmos Gaona, A. (s/d). El secreto en las negociaciones internacionales. La paz del Chaco y el Premio Nobel de la Paz. "Inédito".

PARAdIso, J. (1993). Debates y trayectoria de la política exterior argentina. Buenos Aires: Grupo Editor Latinoamericano.

PeÑa Villamil, M. (1994). "Las relaciones paraguayo-argentinas durante el conflicto del Chaco (1925-1935)”, Anuario de la Academia Paraguaya de la Historia, volumen 23, pp. 169-199.

Perez Stocco, S. (2012). "La neutralidad argentina en la Guerra del Chaco”, Épocas (número 5), enero-junio de 2012, pp. 55-87.

PerinA, R. (1988). "El estudio de la política exterior y las relaciones internacionales argentinas”. En Russell, R. y R. PERINA (eds.). Argentina en el mundo (1973-1983). Buenos Aires: Grupo Editor Latinoamericano, pp. 11-18.

Pomer, L. (1984). Conflictos en la Cuenca del Plata en el siglo XIX. Buenos Aires: Río Inmóvil Ediciones.

Putnam, R. (1988). "Diplomacy and Domestic Politics: The Logic of Two-Level Games”, International Organization, volumen 42 (número 3), verano de 1988, pp. 427-460.

Rapoport, M. y SPiguel, C. (2005). Política exterior argentina. Poder y conflictos internos (1880-2001). Buenos Aires: Capital Intelectual.

Renouvin, P. y DuRosell, J. B. (2000). Introducción a la historia de las relaciones internacionales. México: Fondo de Cultura Económica.

Rittberger, V. (2004). Approaches to the Study of Foreign Policys Derivated from International Relations Theories. Tübingen: Center for International Relations/ Peace and Conflict Studies, Institute for Political Science, University of Tübingen.

Rosenau, J. (1997). Along the Domestic-Foreign Frontier: Exploring Governance in a Turbulent World. Cambridge: Cambridge University Press.

Russell, R. (1990). Política exterior y toma de decisiones en América Latina. Buenos Aires: Grupo Editor Latinoamericano.

SÁNCHEz, L. E. (2013). Condicionantes internos de la política exterior argentina. La participación del cuerpo decisional legislativo en el diseño de la agenda internacional de la política exterior argentina (1999-2003). La Plata-Argentina: Facultad de Humanidades y Ciencias de la Educación, Universidad Nacional de La Plata. Tesis de doctorado en Ciencias Sociales. 
Schenoni, L. y Ferrandi AzTiRia, A. (2014). “Actores domésticos y política exterior en Argentina y Brasil”, CONfines de relaciones internacionales y ciencia política, volumen 10 (número 19), enero-mayo 2014, pp. 113-142.

Smith, P. (1968). Carne y política en la Argentina. Buenos Aires: Paidós.

SolveIRA, B. (1995). Las relaciones argentino-paraguayas a comienzos del siglo XX. Córdoba: Centro de Estudios Históricos.

Stone, L. (1986). El pasado y el presente. México: Fondo de Cultura Económica.

TinI, M. N. (2005). "Las variables domésticas en la política exterior: Argentina y Paraguay”, VII Congreso Nacional de Ciencia Política: “Agendas Regionales en conflicto”. Córdoba: Sociedad Argentina de Análisis Político (SAAP), 15 al 18 de noviembre de 2005.

Valenzuela, P. (2013). Elementos para el análisis de la formulación de política exterior. Santiago: Instituto de Asuntos Públicos para la Universidad de Chile.

VAn Klaveren, A. (1985). "El análisis de la política exterior latinoamericana: perspectivas teóricas”. En MuÑOz, H. y J. TulCHIn (comps.). Entre la autonomía y la subordinación. Política exterior de los países latinoamericanos, Tomo I. Buenos Aires: Grupo Editor Latinoamericano, pp. 14-49.

WiLhelmy, M. (1991). “Los objetivos de la política exterior latinoamericana”, Estudios Internacionales, volumen 24 (número 94) abril-junio de 1991, pp. 176-193.

\section{Fuentes éditas}

Cámara de Diputados de la Nación (1932). Diario de Sesiones, 27 y 28 de septiembre. Congreso de la Nación, Buenos Aires.

— (1933). Diario de Sesiones, 18 y 19 de julio. Congreso de la Nación, Buenos Aires.

. (1933). Diario de Sesiones, 23 y 24 de septiembre. Congreso de la Nación, Buenos Aires.

—_. (1935). Diario de Sesiones, 27 de septiembre. Congreso de la Nación, Buenos Aires.

. (1940). Diario de Sesiones, 6 de septiembre. Congreso de la Nación, Buenos Aires.

Cámara de Senadores de la Nación (1927). Diario de Sesiones, 21 de julio. Congreso de la Nación, Buenos Aires.

. (1933). Diario de Sesiones, 27 y 28 de julio. Congreso de la Nación, Buenos Aires. Aires.

(1933). Diario de Sesiones, 25 de septiembre. Congreso de la Nación, Buenos Aires. 
Cámara de Senadores de la Nación (1939). Diario de Sesiones, 22 de septiembre. Congreso de la Nación, Buenos Aires.

. (1940). Diario de Sesiones, 8 de agosto. Congreso de la Nación, Buenos Aires.

Comisión Económica PARA América Latina y el CARIBe (CEPAL) (1987). Las empresas transnacionales en la economía del Paraguay. Santiago: Organización de las Naciones Unidas.

Rivarola Coello, Vicente (1982). Cartas diplomáticas. Eusebio Ayala. Vicente Rivarola. Guerra del Chaco. Buenos Aires: s/d.

\section{Fuentes inéditas}

División de política, Paraguay y otros (1934). Archivo del Ministerio de Relaciones Exteriores y Culto (AMREC), Buenos Aires.

Dirección de Legajos de Personal (1920-1940). Archivo del Ministerio de Relaciones Exteriores y Culto (AMREC), Buenos Aires.

Fecha de recepción: 26/09/2017

Fecha de aceptación: 04/12/2017 